\title{
Pharmacokinetics of daclizumab high-yield process with repeated administration of the clinical subcutaneous regimen in patients with relapsing- remitting multiple sclerosis
}

\author{
This article was published in the following Dove Press journal: \\ Clinical Pharmacology: Advances and Applications \\ II February 2016 \\ Number of times this article has been viewed
}

\author{
Jonathan Q Tran' \\ Ahmed A Othman ${ }^{2,3}$ \\ Alvydas Mikulskis ${ }^{4}$ \\ Paul Wolstencroft ${ }^{5}$ \\ Jacob Elkins ${ }^{6}$ \\ 'Clinical Pharmacology, Biogen, \\ Cambridge, MA, USA; ${ }^{2}$ Clinical \\ Pharmacology and Pharmacometrics, \\ AbbVie Inc., North Chicago, IL, USA; \\ ${ }^{3}$ Faculty of Pharmacy, Cairo University, \\ Cairo, Egypt; ${ }^{4}$ Global Biomarker \\ Discovery and Development, \\ Cambridge, MA, USA; ${ }^{5} \mathrm{Global}$ Clinical \\ Operation, Biogen, Maidenhead, \\ Berkshire, UK; ${ }^{6}$ Global Clinical \\ Development, Biogen, Cambridge, MA, \\ USA
}

Correspondence: Jonathan Q Tran 2804 Villas Way, San Diego, CA 92108 , USA

Tel + I 4 I5 9995468

Email dr.jtran@gmail.com
Background: Daclizumab high-yield process (DAC HYP), a humanized immunoglobulin G1 monoclonal antibody specific for the $\alpha$ subunit (CD25) of the high-affinity interleukin-2 receptor, has demonstrated efficacy for treatment of relapsing forms of multiple sclerosis in Phase II and III clinical trials.

Objective: To characterize the pharmacokinetics (PK) of DAC HYP following repeated administration of the $150 \mathrm{mg}$ subcutaneous (SC) dose every 4 weeks ( $q 4 \mathrm{wk}$ ), the proposed clinical regimen in patients with relapsing-remitting multiple sclerosis (RRMS).

Methods: Twenty-six patients with RRMS received DAC HYP $150 \mathrm{mg} \mathrm{SC} \mathrm{q4wk}$ for a total of six doses. Serial PK blood samples were collected over the first and last dosing intervals and trough PK samples were collected between these doses. Blood samples for immunogenicity assessment were collected throughout the study. Serum DAC HYP levels and anti-DAC HYP antibodies were characterized using validated immunoassays. PK parameters were estimated using noncompartmental analysis.

Results: DAC HYP showed slow SC absorption with a median time to reach maximum observed concentration $\left(\mathrm{C}_{\max }\right)$ value of $\sim 1$ week. Steady state was reached by the fourth injection. At steady state, DAC HYP mean serum $\mathrm{C}_{\text {max }}$, minimum observed concentration $\left(\mathrm{C}_{\text {min }}\right)$, and area under the concentration-time curve within a dosing interval $\left(\mathrm{AUC}_{\text {tau }}\right.$ ) values were $29.1 \mu \mathrm{g} / \mathrm{mL}$, $14.9 \mu \mathrm{g} / \mathrm{mL}$, and $638 \mu \mathrm{g} \cdot$ day $/ \mathrm{mL}$, respectively, with intersubject variability of $35 \%-40 \%$. The AUC accumulation ratio was $\sim 2.5$ at steady state. DAC HYP had a long elimination half-life of $\sim 22$ days and low apparent clearance $(0.274 \mathrm{~L} /$ day $)$. Nine patients tested positive for anti-DAC HYP antibodies, with no impact on DAC HYP clearance in this limited data set.

Conclusion: The PK of DAC HYP in patients with RRMS are consistent with those previously reported in healthy volunteers. The half-life of $\sim 3$ weeks and the low fluctuations in peak and trough concentrations of serum DAC HYP support the once-monthly SC dosing regimen.

Keywords: pharmacokinetics, daclizumab high-yield process, multiple sclerosis

\section{Introduction}

Daclizumab high-yield process (DAC HYP) is a monoclonal immunoglobulin (Ig) of the human IgG1 isotype that binds specifically to CD25, the $\alpha$ subunit of the human interleukin-2 (IL-2) receptor that is expressed on the surface of activated lymphocytes after interaction with a foreign antigen or in response to IL-2. ${ }^{1}$ It is an investigational product being reviewed by health authorities for the treatment of relapsing forms of multiple sclerosis (MS). In a Phase III study (DECIDE), treatment with DAC HYP $150 \mathrm{mg}$ subcutaneous (SC) dose every 4 weeks (q4wk) in patients with relapsing-remitting 
MS (RRMS) demonstrated superior efficacy in reducing relapse rate compared with $30 \mu \mathrm{g}$ of intramuscular interferon beta-1a, along with a manageable safety profile. ${ }^{2,3}$

The pharmacokinetics (PK) of DAC HYP in healthy volunteers have been reported and are characterized by slow clearance, dose-proportional exposure at doses $\geq 100 \mathrm{mg}$, high SC bioavailability $(\mathrm{F})(>80 \%)$, and an effective half-life of $\sim 3$ weeks. ${ }^{4}$ However, the full PK profile of DAC HYP in patients with MS at the clinical efficacious dose of $150 \mathrm{mg}$ SC q4wk, as confirmed in the Phase III DECIDE study, has not been previously characterized. In this study, we characterized the PK of DAC HYP following multiple-dose administration of the $150 \mathrm{mg} \mathrm{SC} \mathrm{q4wk} \mathrm{regimen} \mathrm{in} \mathrm{the} \mathrm{target}$ patient population.

\section{Methods}

This was an open-label, multicenter, intensive PK substudy, within an immunogenicity study (OBSERVE, NCT01462318), which was conducted in four countries (Czech Republic, Hungary, Poland, and the US). The study was conducted according to the principles of the Declaration of Helsinki and was approved by the following ethics committees: Egészségügyi Tudományos Tanács Klinikai Farmakológiai Etikai Bizottsága, Hungary; Komisja Bioetyczna przy Slaskiej Izbie Lekarskiej w Katowicach, Poland; and Quorum Review Institutional Review Board, WA, USA. All patients provided written informed consent before being included in the study.

\section{Patients and study design}

Patients were eligible to be enrolled in the study if they were 18-65 years old (inclusive); had a confirmed diagnosis of RRMS according to the 2005 McDonald criteria $^{5}$ and previous cranial magnetic resonance imaging demonstrating lesion(s) consistent with MS; had a baseline Expanded Disability Status Scale score of 0-5.0 (inclusive); and had $\geq 1$ clinical relapse(s) within the previous 2 years. Patients were excluded if they had a diagnosis of primary progressive, secondary progressive, or progressive relapsing MS or had previous treatment with daclizumab or another anti-CD25 monoclonal antibody.

Among 113 patients with RRMS participating in the main study, 26 patients were enrolled into the intensive PK substudy. All patients received DAC HYP $150 \mathrm{mg}$ SC injections using the prefilled syringe at the clinic $\mathrm{q} 4 \mathrm{wk}$ for a total of six doses (weeks 0-20) as part of the main study. After completion of the 24-week planned washout period, eligible patients had the option to resume open-label treatment with DAC HYP $150 \mathrm{mg}$ for up to 3 additional years. All patients had to undergo post-dosing safety follow-up evaluations for 6 months after their last dose of DAC HYP.

\section{PK and immunogenicity sampling schedules}

For the 26 patients enrolled in the intensive PK substudy, blood samples for the determination of serum concentrations of DAC HYP were collected at pre-dose, 8 hours, 24 hours, 72 hours, 120 hours, 7 days, 10 days, 14 days, 21 days, and 28 days after dosing at week 0 (dose 1) and week 20 (dose 6). Additional blood samples were collected at 8, 12, 16, and 24 weeks after dose 6 to characterize the elimination half-life of DAC HYP. Additional trough blood PK samples were collected from all 113 patients participating in the main study.

\section{PK and immunogenicity assays}

A validated sandwich enzyme-linked immunosorbent assay method was used to determine DAC HYP concentrations in human serum. In this assay format, microtiter plates were coated with anti-idiotype DAC HYP antibody, followed by blocking, washing, and incubation with 1:100 diluted calibrators, controls, and samples. A biotinconjugated anti-human $\mathrm{IgG}$ was then added to detect bound DAC HYP. After another plate-washing step, horseradish peroxidase (HRP)-conjugated streptavidin was added, and bound HRP conjugate was detected with a tetramethylbenzidine substrate, which was read colorimetrically on a plate reader. The standard curve range is $500-7,500 \mathrm{ng} / \mathrm{mL}$ for DAC HYP in human serum. Samples measuring outside assay limits of quantitation were reanalyzed at an appropriate dilution. If the sample result fell below the lower limit of quantitation $(500 \mathrm{ng} / \mathrm{mL})$ and the sample dilution was at the minimum required dilution (1:100), the result for this sample was reported as below the limit of quantitation.

A multitier methodology was used to evaluate the serum samples for antidrug antibodies (ADAs; anti-DAC HYP antibodies). Samples were first screened for the presence of ADAs via a solution electrochemiluminescent (ECL) assay implemented using the Meso Scale Discovery (MSD) detection platform designed to detect the presence of ADAs in the human serum (Meso Scale Discovery, Gaithersburg, MD, USA). Samples were diluted 1:60 in an assay buffer containing biotinylated DAC HYP (bDAC HYP) and ruthenium-labeled DAC HYP (ruDAC HYP) and incubated overnight at $4^{\circ} \mathrm{C}-8^{\circ} \mathrm{C}$. ADAs present in the samples form bridging complexes with bDAC HYP and ruDAC HYP, and these complexes were captured on a streptavidin-coated MSD plate that had been blocked before use. Only the controls and samples that contained antibodies bound to both 
bDAC HYP and ruDAC HYP were capable of generating a measurable ECL response. The plate was then washed and a tripropylamine (TPA)-containing MSD read buffer was added to the plate. In the presence of TPA and electric current, ruthenium produced a chemiluminescent signal proportional to the amount of ADAs present in the serum. A plate-specific cut point calculated as $1.24 \times$ mean ECL signal of negative control was used to judge the presence of ADAs in a sample. ECL response greater than or equal to a plate-specific cut point was considered ADA-positive in a screening assay.

ADA-positive samples in the screening assays were confirmed in the confirmatory assay. The latter was based on the screening assay and use of excess $(50 \mu \mathrm{g} / \mathrm{mL})$ unlabeled DAC HYP in a competitive binding format to demonstrate the specificity of the binding interactions between ADAs and DAC HYP. Signal inhibition $\geq 22 \%$ confirmed the presence of ADAs in a sample. All confirmed samples were titrated for semiquantitative assessment of ADA titers in the titration assay, which followed the same procedure as the screening assay except that the samples were serially diluted in a negative control matrix prior to the assay. The titer was determined as the reciprocal of the value, calculated by multiplying the minimal required dilution of the assay by the highest serial dilution in the negative control matrix, which yielded a response greater than or equal to the screening assay cut point. At least one diluted sample in a serial dilution series must test negative.

Confirmed ADA-positive samples were also evaluated by the neutralizing antibody (NAb) assay. The assay format was based on coating the MSD 96-well microplate with Kit225 cells - a human T-cell line that expresses IL-2 receptors. The samples and controls were first treated with anti-DAC HYP affinity gel to remove excess DAC HYP, followed by incubating with ruDAC HYP in a polypropylene plate. The sample mixture was then added to an MSD plate coated with Kit225 cells that had been blocked and washed. After incubation, the plates were washed and MSD read buffer was added immediately prior to reading the plate. The ECL signal was proportional to the amount of ruDAC HYP bound to CD25/IL-2R on Kit225 cells. The presence of anti-DAC HYP antibodies decreased the amount of bound ruDAC HYP and the ECL signal. A plate-specific cut point calculated as $0.63 \times$ mean ECL signal of negative control was used to judge the presence of NAbs in a sample. ECL response lower than or equal to a plate-specific cut point was considered NAb-positive.

\section{PK and statistical analysis}

Serum PK parameters for DAC HYP were determined using the actual sample collection times and noncompartmental method (Phoenix ${ }^{\circledR}$ WinNonlin $^{\circledR}$ 6.2.1; Pharsight Corporation,
Sunnyvale, CA, USA). The following PK parameters of DAC HYP were estimated: area under the concentration-time curve within a dosing interval $\left(\mathrm{AUC}_{\text {tau }}\right)$, maximum observed concentration $\left(\mathrm{C}_{\max }\right)$, time to reach $\mathrm{C}_{\max }\left(\mathrm{T}_{\max }\right)$, minimum observed concentration $\left(\mathrm{C}_{\min }\right)$, elimination half-life $\left(\mathrm{t}_{1 / 2}\right)$, and apparent clearance $(\mathrm{CL} / \mathrm{F})$. Accumulation ratio $\left(\mathrm{R}_{\mathrm{ac}}\right)$ was calculated as the ratio of $\mathrm{AUC}_{\text {tau }}$ (dose 6) to $\mathrm{AUC}_{\text {tau }}$ (dose 1). DAC HYP PK parameters were summarized with descriptive statistics by dose. Visual inspections of trough concentration plots versus time were used to assess the attainment of steady state.

\section{Results \\ Patient demographics}

Twenty-six patients with RRMS enrolled in the intensive PK substudy had a mean (range) age of 36.1 (24-54) years and body weight of $77.5(52.0-163.0) \mathrm{kg}$. The majority of the patients were female (65\%) and white (96\%).

\section{Pharmacokinetics}

The mean serum DAC HYP concentration versus time profiles following multiple SC administration of $150 \mathrm{mg}$ of DAC HYP show a monophasic decline (Figure 1), which is likely due to the slow absorption phase masking the distribution phase. After $\mathrm{SC}$ administration, the median $\mathrm{T}_{\max }$ was 7 days after the first dose and 5 days after the sixth (last) dose (Table 1). Serum DAC HYP pre-dose concentrations over the dosing period revealed that steady state was reached by the fourth dose (Figure 2). At steady state, DAC HYP mean serum $\mathrm{C}_{\max }, \mathrm{C}_{\text {min }}$, and $\mathrm{AUC}_{\text {tau }}$ values were $29.1 \mu \mathrm{g} / \mathrm{mL}$, $14.9 \mu \mathrm{g} / \mathrm{mL}$, and $638 \mu \mathrm{g} \cdot$ day $/ \mathrm{mL}$, respectively (Table 1 ).

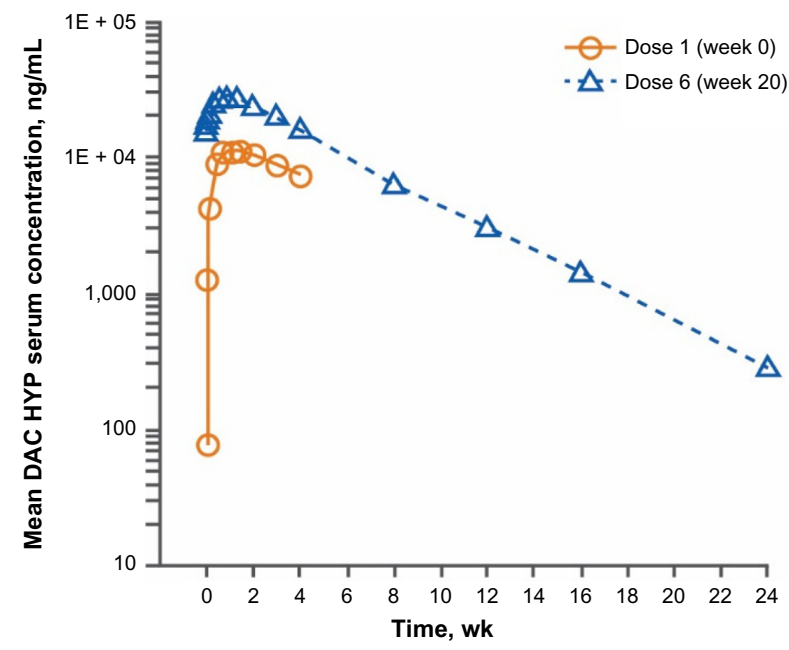

Figure I Mean serum DAC HYP concentration versus time profiles following the first dose (week 0; $=25$ ) and the sixth dose (week 20; $=24$ ) of DAC HYP I $50 \mathrm{mg}$ subcutaneous every 4 weeks in patients with relapsing-remitting multiple sclerosis. Note: IE+04=10,000, IE+05 $=100,000$

Abbreviations: DAC HYP, daclizumab high-yield process; wk, week. 



Figure 2 Serum DAC HYP pre-dose concentrations following administration of DAC HYP I 50 mg subcutaneous every 4 weeks over 20 weeks $(\mathrm{N}=113)$ in patients with relapsing-remitting multiple sclerosis.

Notes: The bottom of each box is the 25 th percentile, the top is the 75 th percentile, and the middle line inside the box is the median. The whiskers extend to $1.5 \times$ the interquartile range, or the maximum and minimum values if there are no outliers. $x$ indicates outliers.

Abbreviations: DAC HYP, daclizumab high-yield process; wk, week.

The percent coefficients of variation for $\mathrm{C}_{\max }, \mathrm{C}_{\min }$, and $\mathrm{AUC}_{\text {tau }}$ were $\sim 35 \%-40 \%$. DAC HYP exhibited a long elimination half-life of $\sim 22$ days (or 3 weeks). A low systemic clearance was observed as judged from the mean $\mathrm{CL} / \mathrm{F}$ of $0.274 \mathrm{~L} /$ day $(11.4 \mathrm{~mL} / \mathrm{h})$ and the previously reported SC bioavailability (F) $>80 \% .{ }^{4}$ Repeated dosing of DAC HYP q4wk resulted in $\sim 2.5$-fold drug $\mathrm{R}_{\mathrm{ac}}$ at steady state (Table 1 ).

In this intensive PK substudy, nine out of 26 patients tested positive for ADAs. The geometric mean $\mathrm{CL} / \mathrm{F}$ values for patients tested negative and positive for ADAs were $0.250 \mathrm{~L} /$ day $(\mathrm{n}=17)$ and $0.260 \mathrm{~L} /$ day $(\mathrm{n}=9)$, respectively. $\mathrm{NAb}$ responses were detected in two patients $\sim 8$ weeks after the last dose. The impact of NAb response on DAC HYP clearance was inconclusive owing to a limited number of patients with NAb response.

\section{Safety and tolerability}

Safety analysis was performed for all 113 patients enrolled in the main study, including patients in the intensive PK substudy. Hence, safety results for 26 patients in the intensive PK substudy are not being reported here. The safety profile of DAC HYP was similar to that observed in previous studies. ${ }^{3}$

\section{Discussion}

DAC HYP is an investigational product being reviewed by health authorities for the treatment of relapsing forms of MS. Two pivotal trials have recently demonstrated robust efficacy and a manageable safety profile of the DAC HYP 
$150 \mathrm{mg}$ SC q4wk regimen in the treatment of RRMS., ${ }^{2,3}$ The population PK characteristics of DAC HYP have been previously evaluated in healthy volunteers following intravenous and SC single- and multiple-dose administration. ${ }^{4}$ The present study characterized the PK of DAC HYP following repeated dosing of the clinical $150 \mathrm{mg} \mathrm{SC}$ dose in 26 patients with RRMS. After SC dosing, DAC HYP showed median $\mathrm{T}_{\text {max }}$ values of 5-7 days, which is comparable to that observed in healthy volunteers (7 days). ${ }^{4}$ The elimination half-life of DAC HYP in patients with RRMS (22 days) also is consistent with that previously reported in healthy subjects (24 days). ${ }^{4}$ Steady state was reached by the fourth dose of DAC HYP, which is expected with the 3-week elimination half-life. DAC HYP clearance was low as judged by the low mean $\mathrm{CL} / \mathrm{F}$ value $(0.274 \mathrm{~L} /$ day) and the previously reported SC bioavailability $(\mathrm{F})>80 \%$. The population $\mathrm{PK}$ results in healthy volunteers projected DAC HYP $\mathrm{C}_{\max }$ to $\mathrm{C}_{\text {trough }}$ ratio of $\sim 2.5$ and the steady-state $\mathrm{R}_{\mathrm{ac}}$ of $\sim 2$ for $\mathrm{SC}$ administration $\mathrm{q} 4 \mathrm{wk} .{ }^{4}$ Results from the present study confirmed these projections. Treatment with DAC HYP $150 \mathrm{mg}$ SC q4wk in patients with RRMS resulted in mean steady-state serum peak-to-trough concentration ratio of $\sim 2$ and $\mathrm{R}_{\mathrm{ac}}$ of $\sim 2.5$.

In this study, ADA responses appeared to have no significant effect on DAC HYP clearance. However, results are not conclusive owing to limited sample size for robust evaluation of impact of immunogenicity on the PK of DAC HYP. The impact of immunogenicity on DAC HYP clearance will be further characterized in the planned population PK data analyses using data from all Phase I-III studies.

\section{Conclusion}

In conclusion, the PK of DAC HYP as characterized in the present study in patients with RRMS are consistent with the previous observations in healthy volunteers. The 3-week elimination half-life and the low fluctuations in serum DAC HYP concentrations support the once-monthly SC dosing regimen.

\section{Acknowledgments}

This study was funded by Biogen and AbbVie Biotherapeutics Inc. The authors acknowledge Yaoshi Wu for his contributions to this analysis. Yaoshi $\mathrm{Wu}$ was a full-time employee of Biogen at the time of the analysis. Biogen and AbbVie Biotherapeutics Inc. provided funding for medical writing support in the development of this paper; Rebecca Jarvis, PhD (Excel Scientific Solutions, Southport, CT, USA), provided editorial support, and Phillip Dingwall (Excel Scientific Solutions, Horsham, UK) copyedited and styled the manuscript per journal requirements. Biogen and AbbVie Biotherapeutics Inc. reviewed and provided feedback on the paper. The authors had full editorial control of the paper, and provided their final approval of all content.

\section{Disclosure}

Jonathan Q Tran was a full-time employee and shareholder of Biogen when this study was conducted and during the development of the manuscript. Alvydas Mikulskis, Paul Wolstencroft, and Jacob Elkins are employees and shareholders of Biogen. Ahmed A Othman is an employee and a shareholder of AbbVie Inc. The authors report no other conflicts of interest in this work.

\section{References}

1. Bielekova B. Daclizumab therapy for multiple sclerosis. Neurotherapeutics. 2013;10(1):55-67.

2. Kappos L, Selmaj K, Arnold DL, et al. Primary results of DECIDE: a randomized, double-blind, double-dummy, active-controlled trial of daclizumab HYP vs. interferon $\beta$-1a in RRMS patients [FC1.1]. Mult Scler. 2014;20(Suppl 1):38.

3. Selmaj K, Kappos L, Arnold DL, et al. Safety and tolerability of daclizumab HYP treatment in relapsing-remitting multiple sclerosis: results of the DECIDE study [P094]. Mult Scler. 2014;20(Suppl 1):109.

4. Othman AA, Tran JQ, Tang MT, Dutta S. Population pharmacokinetics of daclizumab high-yield process in healthy volunteers: integrated analysis of intravenous and subcutaneous, single- and multiple-dose administration. Clin Pharmacokinet. 2014;53(10):907-918.

5. Polman CH, Reingold SC, Edan G, et al. Diagnostic criteria for multiple sclerosis: 2005 revisions to the "McDonald Criteria". Ann Neurol. 2005; 58(6):840-846.

6. Gold R, Giovannoni G, Selmaj K, et al. Daclizumab high-yield process in relapsing-remitting multiple sclerosis (SELECT): a randomised, doubleblind, placebo-controlled trial. Lancet. 2013;381(9884):2167-2175.
Clinical Pharmacology: Advances and Applications

\section{Publish your work in this journal}

Clinical Pharmacology: Advances and Applications is an international, peer-reviewed, open access journal publishing original research, reports, reviews and commentaries on all areas of drug experience in humans. The manuscript management system is completely online and includes a very quick and fair peer-review system, which is all easy to use.

\section{Dovepress}

Visit http://www.dovepress.com/testimonials.php to read real quotes from published authors. 